\title{
URBANIZATION IN BANGLADESH: EMERGING CHALLENGES AND THE WAY FORWARD
}

\author{
Afroza Islam Lipi \\ Lecturer \\ Department of Local Government and Urban Development \\ Jatiya Kabi Kazi Nazrul Islam University \\ Trishal,-Mymensingh, Bangladesh \\ E-mail: afrozaislamlipi@gmail.com \\ Nazmul Hasan \\ Lecturer \\ Department of Public Administration and Governance Studies \\ Jatiya Kabi Kazi Nazrul Islam University \\ Trishal, Mymensingh, Bangladesh \\ E-mail: nazmul.pags23@gmail.com
}

\begin{abstract}
Urbanization is a natural process of the population shift from rural to urban territories. More specifically, urbanization is a process of migration of population from rural to urban areas as well as the transformation of society where the rural agricultural economy is being transformed to advance the industrial economy. A major change to be witnessed in Bangladesh over the last few decades is the rapid spread of urbanization. Multiple driving factors paved the way for spreading the rapid growth of urbanization in Bangladesh. If this spread is not effectively managed, emerging challenges like spatial imbalance, environmental challenges, weak policy framework, challenges of sustainable cities, urban poverty, urban health issues, etc are likely to grow. This study aims at exploring the emerging challenges of urbanization in Bangladesh. It also explores the way forward to face the emerging challenges. This study has been conducted depending on qualitative and descriptive analysis. It is mainly based on secondary data. Available books, journals, documents, newspapers, data, reports, and magazine articles are reviewed in detail as a secondary source. In the findings of the study, the rapid growth trend has been critically examined. Besides emerging challenges of urbanization in Bangladesh have been identified. Finally, some recommendations have been put forward to overcome the emerging challenges of urbanization in Bangladesh.
\end{abstract}

Keywords: Bangladesh, Challenges, Urbanization.

JEL Classification Codes: D8, O15, O18.

\section{INTRODUCTION}

The history of urbanization is the history of people struggle to survive and to move from rural to urban areas in search of better opportunities which are absent in the villages or rural areas. In the 
past, people were satisfied with their rural simple life, but nowadays various factors work behind the rapid growth of urbanization such as job opportunities, better service facilities, better income, educational facilities, better standard of living, etc. The growth of cities and urbanization of the world is one of the most impressive facts of modern times which wrought profound changes in virtually every phase of social life (Writh, 1938). Urbanization is an inevitable and dynamic process. It has a long urban history through towns and cities that appeared many years ago, the process of modern urbanization first began with the industrial revolution in England and then in all the continents of the world. The 21 st century is becoming an urban century. Urbanization is a word that describes the increase in the proportion of people living in urban areas such as towns and cities. Urban growth is an unavoidable feature in the process of urbanization. In recent times, the tendency of people to live around cities and towns in Bangladesh is increasing day by day. In our country, people mainly come from villages to cities in search of multiple opportunities. However, urbanization is frequently used as an indicator of development. But unplanned urbanization is a threat in developing countries like Bangladesh. Recently, some contemporary emerging challenges are complicating urbanization in Bangladesh. Proper planning and measures can reduce such emerging challenges, and their impact. Through planned urbanization, Bangladesh will surely achieve its desired sustainable urban development goal. In 2008, humankind has crossed a socio-demographic milestone for the first time in history by having half of its population living within the urban areas (UNFPA, 2007). Ultimately urbanization accelerates the major socioeconomic and infrastructural transformation of the country with other related changes. Bangladesh is urbanizing fast with a new idea for new ways of creating better human life. So, the study of urbanization in Bangladesh is a crucial issue today. Various contemporary emerging challenges need to identify and address challenges for making sustainable cities in Bangladesh.

\section{Objectives of the Study}

This study focuses on urbanization and the emerging challenges in Bangladesh. It suggests some ways forward measure as well. The objectives of this study are:

- To examine the nature and trends of urbanization in Bangladesh.

- To explore emerging challenges of urbanization.

- To make the way forward measures.

\section{LITERATURE REVIEW}

Urbanization is not a modern phenomenon. It has a long historical culture. During the last few decades, Bangladesh has experienced an extremely high rate of urbanization. Urbanization is a pattern of change from rural life to urban life. Misra (1978) explained, "urbanization is a process of change in the demographic, social, economic, technological, and environmental context of life in a given society. These changes reveal themselves in the growing concentration of population in human settlements larger than rural areas. (Misra, 1978). Estimates show that the gradual shift of population from rural to urban areas, combined with the global population growth, could add another 2.5 billion people to urban areas by 2050, with close to $90 \%$ of this increase taking place in Asia and Africa, according to United Nations data 2019. Since independence, the average rate of urbanization in Bangladesh is 5\% (World Bank, 2012) and the rate has been increased tremendously. The first Bangladesh census completed in 1981 shows a low level of urbanization where only $15 \%$ of the total population lived in cities (Farhana, 2015). But recently our country has experienced a high rate of growth in its urban area. A variety of driving factors has been 
identified to explain rapid urbanization in Bangladesh. The micro-credit program is very popular to reduce poverty and improve the standard of living both in rural and urban areas. Sometimes rural people cannot repay micro-credit loans in time due to the high-interest rate of credit and very short time of repayment loan etc (Banu, Hossain, Haque, \& Ahmed, 2021). As a result, people moved to the urban areas in search of new jobs to pay off their loans. A lot of economic opportunities such as industrialization, infrastructure, commercialization, trading, etc result in rapid urbanization in Bangladesh. The contribution of the urban sector to GDP is increasing gradually in Bangladesh and it is now about $65 \%$. Due to industrialization, more and more people are moving from rural areas to urban areas for better employment. Hofmann and Wan (2013) examined that trade promotes urbanization through at least two channels: (1) Trade development is accompanied by growth in transportation hubs, which are usually located in cities; and (2) The setup and maintenance of international trade connections increase demand for marketing and financing services that also concentrate on cities (Hofmann \& Wan, 2013). So, modern trade and commerce have also resulted in rapid urbanization. The role of infrastructure has been prominently featured in the core-periphery literature that analyzes urban concentration in core regions, and periphery regions in the presence of technological progress, which is often indicated by lower transport costs (Wan \& Zhang, 2017). At the end of the 20th century in the 1980 s, the garment industries grew to start, and still, now, there are 4296 factories. The growth of such industries drives rapid urbanization in Dhaka and other cities. In this regard, a large proportion of people migrated from rural to urban areas in search of a better life with a job in factories. As a result, urbanization started to grow in faster motion. A report from BGMEA (2019) showed the rise of working people and the number of garment factories in the last 30 years. In 1985, only 120000 people worked in 384 garment factories. After 15 years the number of people and factories were increased. After 15 years in 2000, around 1.6 million workers in 3200 garments factories and again more than 15 years in 2015, 4 million workers in 4296 factories. This industrial boom is one of the major driving factors for rapid urbanization in recent times (BGMEA, 2019). Nazrul Islam in his writing ' Urbanization in Bangladesh: Recent Trends and Challenges' mentioned various challenges of urbanization in Bangladesh briefly. He added urbanization brings along economic and social benefits, but it also poses some serious challenges, especially when it takes place at a pace as rapid as the one in evidence in Bangladesh today (Islam, 2018). Islam examined that, rapid urbanization without planning and development control has led to massive degradation in the urban environment. This is evident in air and water pollution. There is also a high level of noise pollution and land degradation. Uncollected garbage adds to an increase in harmful odors as well. In big cities particularly Dhaka, air pollution is one of the highest in the world. Lots of traffic jams have become a regular feature. In addition to contributing to the pollution of air, traffic jams also cause economic loss. It has been caused by rapid urbanization. There is very little planning activity, and urban management is weak and uncoordinated. The situation has been created for a long time. Lack of adequate financial resources is also an important issue, but equally critical has been the lack of awareness on the part of the authority as well as of the people. Deforestation, cutting down of hills, encroachment, and filling of reservoirs, or other situations are caused mainly due to overpopulation, and poor governance (Islam, 1999). Rapid urbanization creates the challenge of disaster vulnerabilities in our cities. Disaster risks are obvious and immediate, and they gesture special challenges. Bangladesh was known for rural hazards previously, but nowadays urban hazards are becoming severe day by day. In this regard, many governmental and non-governmental initiatives have been launched to reduce disaster vulnerabilities. But there is still much to be done (Rahman, 
Islam, \& Ahmed, 2012). In the context of Bangladesh, the challenges of future urbanization are enormous. Poor management, inefficiency, and lack of coordination among implementing agencies combined with inadequate financial resources have been aggravating the situation. Proper planning, and well-thought-out strategy, strong coordination, and a compact implementation plan supported by ample finance are necessary (Zaman, Alam, \& Islam, 2010). To reduce the flow of rural-urban migration, balanced development is urgently needed. Otherwise, Dhaka city may be the worse place in the entire world. So Government should make and implement sustainable urban policy. Besides, a strategic plan can encourage resisting urban growth. To make sustainable and healthy Dhaka city, proper management is essential. Urban administration should make a proper effort to improve the overall conditions of livelihood of urban poor (Sohel, Islam, \& Muhibbulah, 2017). Reviewing the above research literature, it appears that while there are many research works on urbanization in Bangladesh but it is a considerable shortage of details and updated work on contemporary emerging challenges of urbanization in Bangladesh. The content of this article is about the nature and the trends of urbanization and unplanned rapid urbanization as well as emerging challenges. It also attempts to discuss the updated concept of Urbanization and to make the way forward measures to overcome emerging challenges. So hopefully this research will contribute to explore a detailed analysis of emerging challenges and the way forward of urbanization in Bangladesh, and filling the prior gap.

\section{METHODOLOGY}

This study has been conducted depending on a broad descriptive and analytical approach. It is mainly based on secondary data. Secondary data has been collected from different published materials like the publication of the United Nations, World Bank, Worldometer, and relevant writings of some scholars. The data from the year 1955 to 2020 have been analyzed to evaluate the trends of urbanization in Bangladesh, and the emerging challenges of urbanization have been explored. The collected data has been processed and prepared to make the study more informative, analytical, and useful for the readers, and the researchers.

\section{FINDINGS OF THE STUDY}

Reviewing previous literature, in this section, there is an attempt to identify multiple challenges and the way forward. First of all, nature and the trends should be examined.

\section{The Nature of Urbanization}

Urbanization is an ongoing process. At present, the issue of urbanization is very important in Bangladesh. The following features are found when analyzing the nature of urbanization. Such as -

- Urbanization is a dynamic process of social transformation.

- Densely populated in small areas.

- Slum areas are available in the city to create housing for the urban population.

- Municipalities, city corporations, or local governments are the governing bodies of urban areas.

- The main center of industrial production, business, trade, etc is located in urban areas

\section{The Trends of Urbanization}

Bangladesh has a long history of urbanization. At the beginning of the 20th century in 1901, only $2.43 \%$ (or about 0.7 million) of the total population of present Bangladesh areas of British India lived in urban areas. In the first half of the century, urban population growth was almost static. In 
1941 , less than $4 \%$ of the population lived in urban centers, and the total urban population was 1.54 million. Urbanization got impetus after 1947, when the Indian subcontinent became free of British rule creating the two independent states, India and Pakistan, with East Bengal (presentday Bangladesh) as the eastern part of Pakistan. Between 1951-1961, there was significant growth in the urban population (45.11\%) compared with the 1941-1951 period (18.38\%). The total urban population increased from 1.8 million in 1951 to about 2.6 million in 1961. The important reason behind this rapid growth was the large-scale migration of Muslims from India after 1947, who mostly settled in urban areas (Banglapedia, 2012). Urbanization has slowed down during the beginning of the 20th century. The following table shows a very low share of the total population lived in urban areas in 1955 when only $4.7 \%$ people lived in cities. After the independence of Bangladesh in 1975, the share increased from 4.7\% to $10.0 \%$. The level of urbanization is increasing but at a decreasing rate. The growth of urbanization took place during the period from 1980 to 2000 . It is said that the 21st century is becoming an urban century. This perception and projection have developed all over the world even in Bangladesh. Approximately 64.81 million people are living in urban areas in 2020 in our country. This was an increase from 2005, in which approximately 38.45 million people in Bangladesh were living in urban areas. Between the end of the 20th century and the beginning of the 21 st century, multiple driving factors paved the way for rapid urbanization. In 2010, urban population increased to $31.4 \%$ from $24.3 \%$ in 2000 . In 2015, this rose to $35.4 \%$. As in previous decades, both migration and natural growth contributed to this growth. But the most important contributory factor for recent times is the development of industrial sectors and changes in sociopolitical conditions. Now $39.4 \%$ of people live in urban areas in 2020. That means about $40 \%$ of people are now living in cities whereas, only $10 \%$ people lived in cities after independence in 1975 . The level of urbanization is shown in the following table -

Table1. Level of Urbanization in Bangladesh

\begin{tabular}{|l|l|l|l|}
\hline Year & Total Population & Urban Population & Urban \% of population \\
\hline 2020 & 164689383 & 64814953 & 39.4 \\
\hline 2015 & 156256276 & 55305132 & 35.4 \\
\hline 2010 & 147575430 & 46347089 & 31.4 \\
\hline 2005 & 139035505 & 38452976 & 27.7 \\
\hline 2000 & 127657854 & 31040651 & 24.3 \\
\hline 1995 & 115169930 & 25751454 & 22.4 \\
\hline 1990 & 103171956 & 21037450 & 20.4 \\
\hline 1985 & 90764183 & 16305971 & 18.0 \\
\hline 1980 & 79639491 & 12099053 & 15.2 \\
\hline 1975 & 70066301 & 7013461 & 10.0 \\
\hline 1970 & 64232482 & 4938975 & 7.7 \\
\hline 1965 & 55385112 & 3467675 & 6.3 \\
\hline 1960 & 48013504 & 2474987 & 5.2 \\
\hline 1955 & 42086301 & 1974441 & 4.7 \\
\hline
\end{tabular}

Source: Worldometer, 2020a

From the above information, we can get rapid trends of urbanization in Bangladesh. 


\section{Emerging Challenges}

Due to the rapidly growing population, cities are facing multiple emerging challenges. The emerging challenges are described in this section. These are given below-

\section{Spatial Imbalance}

Rapid urbanization creates the challenge of spatial imbalance between the rural and urban proportion of the population. The spatial imbalance and the changes of share of rural and urban population for the last 60 years in Bangladesh is shown in the following table -

Table 2. Level of urbanization with the share of the rural and urban population

\begin{tabular}{|l|l|l|l|l|}
\hline Year & Rural population & $\begin{array}{l}\text { Rural \% of } \\
\text { population }\end{array}$ & Urban population & $\begin{array}{l}\text { Urban \% of } \\
\text { population }\end{array}$ \\
\hline 2020 & 99874430 & 61 & 64814953 & 39 \\
\hline 2015 & 100951144 & 65 & 55305132 & 35 \\
\hline 2010 & 101228341 & 69 & 46347089 & 31 \\
\hline 2005 & 100582529 & 72 & 38452976 & 28 \\
\hline 2000 & 96617203 & 76 & 31040651 & 24 \\
\hline 1995 & 89418476 & 78 & 25751454 & 22 \\
\hline 1990 & 821345506 & 80 & 21037450 & 20 \\
\hline 1980 & 67540438 & 85 & 12099053 & 15 \\
\hline 1970 & 59293507 & 92 & 4938975 & 8 \\
\hline 1960 & 45538517 & 95 & 2474987 & 5 \\
\hline
\end{tabular}

Source: Worldometer, 2020b

Currently, $39 \%$ of the population of Bangladesh is urban (64814953-people in 2020). On the other hand in 2020,61\% of the population of Bangladesh is rural which $95 \%$ was in 1960. By 1960-70, the total population of Bangladesh was 70 million, of which only $6 \%$ lived in cities and a large portion of the population lived in rural areas. At that time it was identified that very low tendency of urbanization. But gradually percentage of the rural population is decreasing and the urban rate is increasing. Such rapid urbanization causes an imbalance between rural and urban population growth.

\section{Urban Health Issues}

Due to massive urbanization in Bangladesh, our cities are gradually losing their livability. And as a result, public health in urban areas is in dire straits. Infectious and non-infectious diseases are on the rise in the city due to air, water, noise pollution, mismanagement of waste, declining greenery, rising temperatures, etc. This increases our mental and physical health risks. Many people live in unhealthy slums in urban areas also; this population density of slums is a major cause of health risks in the city. Lack of potable water, toxic air, poor sewerage management, and lack of sanitation and waste management have put our cities at the bottom of the global index. The health of the urban poor or slum dwellers is primarily due to overcrowding and inadequate access to basic services, such as water and sanitation. Effects of these living conditions include stress due to crowding, insecurity due to lack of housing and land tenure, various types of illegal or criminal activities, including violence, drug use, prostitution, etc (Streatfield \& Karar, 2008). 


\section{Unplanned Urban Growth}

Unplanned urbanization is one of the contemporary challenges in recent times. There is an upward trend in all areas along with the level of urbanization. During the British colonial rule up to 1947 , the level of urbanization was low. Thereafter, the pack of urbanization got momentum and continued till 2000 and is still maintaining an upward trend. It is difficult to make proper planning for such a dramatic upward fashion of urbanization. In most cases, there has no proper planning to maintain urban growth. As a result, unplanned urban growth is continuing in Bangladesh. Without proper planning, massive urbanization creates unplanned urban growth in cities and towns.

\section{Rapid Growth of Population in Cities}

At present, the population of cities in Bangladesh is increasing at a tremendous rate. The abovementioned table named 'level of urbanization' shows the trends of urban population growth. At present, about $40 \%$ of people live in cities. Such estimation proves the rapid growth of the population in cities. Overpopulation in cities is responsible for extreme traffic, the depletion of resources, pollution, and unemployment among many other challenges. Due to the rapid growth of population in urban areas, excessive pressure on urban utility services, infrastructure, environment, etc. may lead to disaster in the livability and urban health of the city.

\section{Challenges of Sustainable Cities}

Rapid urbanization in the cities of developing countries as Bangladesh has been a dilemma of economic development and environmental sufferings (Akash, Jesmin, Tamanna, \& Kabir, 2018). Sustainability of cities refers to economically viable, environmentally friendly, and socially peaceful. But nowadays, it is observed various challenges regarding the sustainability of cities in Bangladesh. Such as - Air, water, and noise pollution constitute environmental pollution in the cities which hamper its sustainability. The massive growth of industrialization causes unhealthy environmental conditions in cities. Ultimately, our cities are suffering from inadequate infrastructural services, environmental degradation, social insecurity which are the major threats to make sustainable cities in Bangladesh.

\section{Urban Poverty}

The global shift in the distribution of the world's population in urban areas has led to the increase of poverty in cities. With the rapid urbanization in developing countries, urban poverty concentrates. In some countries, urban poverty is more significant than in rural areas (Zhang, 2016). It has been shown from the trends of urbanization in Bangladesh that the urban growth rate is increasing gradually. This hasty urbanization creates a burden on cities and towns and aggregates urban poverty. Such kind of urban poverty causes serious challenges to the cities, most importantly, the issue of health and housing.

\section{Environmental Challenges}

Due to rapid urbanization, reservoirs, open spaces, and parks in various cities are rapidly shrinking, and biodiversity, which is very important for urban life, including plants and animals, is under serious threat today. Environmental pollution in urban areas is a burning issue in recent times. Air pollution is one of them. The main reasons for higher levels of air pollution in urban areas than in rural areas are exhaust fumes from various types and sizes of vehicles, toxic fumes from industrial plants, black smoke from brick kilns, smoke from burning tires and plastics. In 
addition, burning of bitumen used in road repairs in urban areas, a gas emitted from AC, running photocopy machines, mosquito coils, aerosols, brick breaking machines, and tear gas used by the police for security are significantly responsible for air pollution in urban areas. Moreover, household dust, street dust, and urban areas are some of the elements of air pollution. Issues related to water and sanitation is surfacing due to rapid population growth. The population of cities is suffering from a lower standard of living due to environmental challenges such as water scarcity, sanitation, and multiple environmental pollutions. Besides, it leads to the spread of diseases, and poor health in heavily populated areas as well. Cities and towns have made a major contribution to climate change through the creation of Green House Gases(GHGs) emerged from energy supply for electricity generation (coal, gas, and oil); transportation; energy use in commercial and residential buildings for lighting, cooking, space heating, and cooling, industrial production, and waste (Rahman, Islam, \& Ahmed, 2012).

\section{Challenges of Urban Utilities and Services}

Unplanned rapid urbanization is having an adverse effect on the social and natural environment. The rapid population growth in the city is putting huge pressure on the city services. Ensuring utility services like housing, education, medical, water supply, electricity, sewerage, communication facilities, waste management, etc. has become a big challenge. If unplanned urbanization continues, it will be almost impossible to ensure these existing urban services for all.

\section{Vulnerability in Urban Transport System}

Rapid urbanization has increased the traffic pressure in the cities of Bangladesh. As a result, the black smoke from vehicles is polluting the environment. Additionally, the traffic congestion on the city roads is also increasing. The transportation system is one of the major determinants of urbanization in cities. The existing transportation system of cities is not developed enough to manage the situation. There are various types of vehicles like rickshaws, motorbike, auto bike, taxi, CNG, truck, bus, microbus, minibus, private car, motor vehicles, van, etc. The worse fact is that still today there are not developed rail facilities that would be possible under proper urbanization process. To deal business occupying footpath, no special car parking system, more vehicles and do not maintain traffic rules and regulations are mainly responsible for creating a traffic jam. Noise pollution, air pollution, waste of time, emitting carbon and greenhouse gas are the common effects of traffic jam that causes the respiratory disease to the city dwellers. The lack of effective transportation planning, lack of proper legal and administrative framework, insufficient technical skills, etc cause vulnerability in the urban transport system (Bapari, Haque, Chowdhury, \& Islam, 2016).

\section{Weak Policy Framework}

The status of urban planning and development policies is diverse in Bangladesh but not profound. Bangladesh still does not have any sole policy for urban development. Most of the fundamentals and essential rules and regulations are failing to respond to the contemporary need in the absence of amendments such as the Town Improvement Act, 1953, which is old enough to address the current urban challenges concerning urbanization. The Ministry of Local Government took the initiative to formulate a 'policy' in 2004 for the planned development of urban areas of the country. The draft was finalized in 2014 with changes, refinements, and 
corrections. This is known as Urban Development Policy 2014. But it has not been implemented yet.

\section{The Way Forward}

The rapid urbanization in Bangladesh has accelerated various cultural, socioeconomic, and political progresses but this rapid growth is facing enormous challenges too. So, urbanization is not only bringing fortune to us but it bears some adverse effects as well. It should take some ways forward measures to prompt urbanization in Bangladesh. Such as -

- To reduce uneven urbanization or spatial imbalance, there is no alternative to provide urban services at the rural level. In this regard, a project named my village, my city has been initiated by the government.

- Assuring health facilities, safety, and security of basic needs of all citizens through multiple initiatives. To protect urban health by ensuring affordable and quality housing for all, and ensuring disease control, and human well-being by developing solid waste and sewage management as well as the city's environment.

- Creating area-based primary health centers through proper planning as well as ensuring affordable and accessible health services for all in urban areas and eliminating social inequalities in public health protection.

- Proper planning should be taken to reduce unplanned urbanization and rapid population growth in cities. Adequate steps and legal measures should be taken to reduce urban crime and violence.

- Ensuring sustainable development by creating a livable environment in urban areas by reducing all types of environmental pollution including air pollution, water pollution, noise pollution, etc.

- Urban poverty should be minimized by enhancing income-generating methods and improving productivity as well as eradication of poverty through appropriate regulatory frameworks and infrastructure provisions.

- It is needed to protect, preserve and enhance the urban environment, particularly water and air pollution should be reduced and ensuring access to area-based playgrounds, parks, reservoirs, gardens, and accesses to all to ensure the health of people of all classes, professions, and ages.

- To build human settlements and society by creating public spaces, recreational facilities, community centers and organizing regular social events to increase the opportunities for socialization to ensure mental health.

- Various Urban utility services such as health, education, water, and sanitation, housing should be expanded to villages and providing income-earning opportunities to reduce rural-urban disparities. Besides, an urban transport system should be developed and to increase rail transport facilities to reduce traffic congestion on urban roads.

- To formulate a city plan by determining the desired population and area-based population density on the amount of existing civic services and community facilities, road and drainage infrastructure, parks-playgrounds-reservoirs-open space, etc.

- A comprehensive National Urban Sector Policy should be implemented for maintaining rapid urbanization in Bangladesh. 


\section{CONCLUSION}

In fine, it can be said that there was a low tendency of the urbanization in our country. Most of the people were living happily in their villages working in the agricultural sector. But with the change of time, the needs of people are also changing. At present, one-third of the total population is now living in urban areas. It is a concerning issue for our country. If we do not manage the impetuous urban growth, we will suffer in the long run. Urbanization makes a vital contribution to the socio-cultural, political, and economic upliftment of the country. People are attracted to be urbanized in the search of a better food supply, reducing poverty, multiple job opportunities, the proper infrastructure like roads, water, electricity, etc. a wide variety of entertainment, availability of services like health, education, postal, police station and so on. If urban growth and development are poorly managed, it will emerge multiple challenges. The study tries to examine the trends of urbanization and the emerging challenges. Additionally, the various way forward measures are mentioned in the above discussion. In the long run, urbanization should be planned. Most importantly a comprehensive urban development policy must be implemented to overcome emerging challenges.

\section{ACKNOWLEDGEMENT}

We are thankful to the Almighty Allah for the good health and well-being that was necessary to prepare this paper. This study becomes successful with the kind support of many individuals. We would like to express our gratitude to the all respected teachers of our department to encourage us. We also thank our family members, our colleagues, and friends for their encouragement, support, and attention.

\section{CONFLICT OF INTEREST}

The authors declare no conflicts of interest concerning the present research work.

\section{REFERENCES}

Akash, M., Jesmin, A., Tamanna, T., \& Kabir, M. R. (2018). The Urbanization and Environmental Challenges in Dhaka City. SSRN Electronic Journal, 145-157.

Banglapedia. (2012). Urbanisation. $\quad$ Retrieved from http://en.banglapedia.org/index.php?title=Urbanisation

Banu, B., Hossain, M. M., Haque, M. S., \& Ahmed, B. (2021). Effect of Microfinance Adoption on Rural Household Income in Selected Upazila of Kushtia District of Bangladesh. Bangladesh Journal of Multidisciplinary Scientific Research, 3(1), 24-32.

Bapari, M. Y., Haque, M. E., Chowdhury, D. K., \& Islam, M. J. (2016). Impacts of Unplanned Urbanization on the Socio-Economic Conditions and Environment of Pubna Municipality, Bangladesh. Journal of Environment and Earth Science, 6(9), 105-114.

BGMEA. (2019). Trade $\quad$ Information. $\quad$ Retrieved from http://www.bgmea.com.bd/home/pages/TradeInformation

Farhana, T. (2015). Digital Development. Retrieved from https://www.worldbank.org/en/topic/digitaldevelopment 
Hofmann, A., \& Wan, G. (2013). The Asian Development Bank (ADB): Working Paper Series. Retrieved from https://www.adb.org/publications/series/economics-working-papers

Islam, N. (1999). Urbanisation, Migration and Development in Bangladesh: Recent Trends and Emerging Issues. Retrieved from https://cpd.org.bd/paper-1-urbanisation-migration-anddevelopment-in-bangladesh-recent-trends-and-emerging-issues/

Islam, N. (2018, October 23). Urbanisation in Bangladesh: Recent Trends and Challenges. Retrieved from https://www.daily-sun.com/post/345303/Urbanisation-in-Bangladesh:Recent-Trends-and- Challenges

Misra, R. P. (1978). Million Cities of India. New Delhi, India: Vikas Publishing House Pvt Ltd.

Rahman, M. S., Islam, B., \& Ahmed, B. (2012). An overview on Rapid Urbanization and Induced Disaster Risk Factors in Bangladesh. In Planned Town: Balanced Development (pp. 56-65). Bangladesh Institute of Planners.

Sohel, M. S., Islam, M. M., \& Muhibbulah, M. (2017). Rural-Urban Migration Transition in Bangladesh. Scholars Journal of Arts, Humanities and Social Science, 5 (12(A)), 18081816.

Streatfield, P. K., \& Karar, Z. A. (2008). Population Challenges for Bangladesh in the Coming Decades. Journal of Health, Population and Nutrition, 26(3), 261-272.

UNFPA. (2007). State of World Population 2007: Unleashing the Potential of Urban Growth. Retrieved from https://www.unfpa.org/publications/state-world-population-2007

Wan, G., \& Zhang, Y. (2017). Accelerating Urbanization Explained: The Role of Information. Retrieved from https://www.adb.org/publications/accelerating-urbanization-explainedrole-information

World Bank. (2012). Bangladesh: Towards Accelerated, Inclusive and Sustainable GrowthOpportunities and Challenges. Bangladesh: World bank.

Worldometer. (2020a). Bangladesh Population. Retrieved from https://www.worldometers.info/world-population/bangladesh-population/

Worldometer. (2020b). Bangladesh Demographics. Retrieved from https://www.worldometers.info/demographics/bangladesh-demographics/\#urb

Writh, L. (1938). Urbanism as a Way of Life. American Journal of Sociology, 44(1), 1-24.

Zaman, A. H., Alam, K. M., \& Islam, M. J. (2010). Urbanization in Bangladesh: Present Status and Policy Implication. ASA University Review, 4 (2). 
Zhang, X. Q. (2016). The trends, promises, and challenges of urbanisation in the world. Habitat International, 54 (3), 241-252.

\section{Copyrights}

Copyright for this article is retained by the author(s), with first publication rights granted to the journal. This is an open-access article distributed under the terms and conditions of the Creative Commons Attribution license (http://creativecommons.org/licenses/by/4.0/) 